\title{
Pathogenesis of multiple sclerosis: expression of HERV-FC1: a human endogenous retrovirus
}

\author{
Magdalena Janina Laska ${ }^{*}$, Tomasz Brudek², Kari Konstantin Nissen', Tove Christensen ${ }^{1}$, Anne Møller Larsen', \\ Thor Petersen ${ }^{3}$, Bjørn Andersen Nexø ${ }^{1}$ \\ From Frontiers of Retrovirology 2011 \\ Amsterdam, The Netherlands. 3-5 October 2011
}

\section{Background}

Multiple Sclerosis (MS) is considered to be an autoimmune disease with unknown cause and with immune system dysregulation. Among environmental factors, viruses are most often connected with the etiology of MS.

Human Endogenous Retroviruses (HERVs) constitute $5-8 \%$ of human genomic DNA and have been detected as transcripts and proteins in the central nervous system (CNS) and peripheral blood, frequently in the context of neuro inflammation [1,2].

In our recent genetic epidemiology study in MS patients [3] we found indications of a specific genetic association between HERV-Fc1 (which belongs to the HERV-H/F family) and MS. One marker neighboring HERV-Fc1 (rs391745) had a $p$-value of $1.3 \times 10^{-6}$ for disease association in a trend test.

\section{Materials and methods}

Using polyclonal rabbit antibodies raised against a Gag peptide, conserved in the HERV-H/F family, the authors studied the expression of a capsid protein of HERV-H/F origin by flow cytometry in PBMCs from healthy controls and from MS patients with non-active or active disease. Furthermore, we have undertaken the first rigorous SYBR green-based absolute Q-PCR evaluation approach to quantify extracellular HERV-Fc1 RNA viral loads in plasma from patients with MS and healthy controls.

\section{Results}

We showed significant differences in the expression of HERV-H/F Gag protein epitopes between PBMCs from

\footnotetext{
${ }^{1}$ Department of Biomedicine, Aarhus University, 8000 Aarhus C, Denmark Full list of author information is available at the end of the article
}

healthy controls and from MS patients. We found higher HERV-H/F Gag expression in peripheral blood CD19+ cells and significantly higher expression in monocytes in patients with non-active MS than in healthy controls. For patients with active MS, much higher differences in the HERV-H/F Gag expression relative to healthy controls were detected for $\mathrm{CD} 4+$ and CD8+ T cells indicating that this HERV family may play a role in the extensive activation of the innate and adaptive immune responses in MS. Also for patients with active MS, the expression of HERV-H/F Gag by CD4+ $\mathrm{T}$ cells was significantly higher than that by $\mathrm{CD} 8 \mathrm{a}+\mathrm{T}$ cells.

Extracellular HERV-Fc1 RNAs were detected in plasma samples from both healthy controls and from MS patients. In plasma samples from patients with nonactive MS, higher levels of extracellular HERV-Fc1 RNAs were found as compared with healthy controls. Moreover, a 5-fold increase of the amount of extracellular HERV-Fc1 RNA was found in plasma samples from patients with active MS as compared with healthy controls.

\section{Conclusions}

These findings strengthen the link between HERV-Fc1 and the pathology of MS. The cause and biological consequences of these differential expressions will be the subject of further investigation. HERV-Fc1 biology could be a compelling area for understanding the pathology of MS and possibly other autoimmune disorders.

\section{Author details}

'Department of Biomedicine, Aarhus University, 8000 Aarhus C, Denmark. ${ }^{2}$ Research Laboratory for Stereology and Neuroscience, Bispebjerg University Hospital, 2400 Copenhagen NV, Denmark. ${ }^{3}$ Department of Neurology, Aarhus University Hospital, 8000 Aarhus C, Denmark. 


\section{References}

1. Christensen T: HERVs in neuropathogenesis. J Neuroimmune Pharmacol 2010, 5:326-35,

2. Brudek T, Christensen T, Aagaard $L$, et al: B cells and monocytes from patients with active multiple sclerosis exhibit increased surface expression of both HERV-H Env and HERV-W Env, accompanied by increased seroreactivity. Retrovirology 2009, 6:104.

3. Nexø BA, Christensen T, et al: The etiology of multiple sclerosis: genetic evidence for the involvement of human endogenous retrovirus HERVFc1. PLOS ONE 2010, 2:e16652.

doi:10.1186/1742-4690-8-S2-023

Cite this article as: Laska et al:: Pathogenesis of multiple sclerosis: expression of HERV-Fc1: a human endogenous retrovirus. Retrovirology 2011 8(Suppl 2):O23.

\section{Submit your next manuscript to BioMed Central} and take full advantage of:

- Convenient online submission

- Thorough peer review

- No space constraints or color figure charges

- Immediate publication on acceptance

- Inclusion in PubMed, CAS, Scopus and Google Scholar

- Research which is freely available for redistribution

Submit your manuscript at www.biomedcentral.com/submit 